\title{
ARGAMASSA GEOPOLIMÉRICA À BASE DE LODO DE ESTAÇÃO DE TRATAMENTO DE ÁGUA CALCINADO PARA REPARO DE ESTRUTURAS DE CONCRETO
}

\author{
PEDRO FERREIRA CAVALCANTE, BRENO \\ Graduando em Engenharia Civil \\ Instituto de Tecnologia da Universidade Federal do \\ Pará, FEC - GAEMA - ACGEO \\ Pará, Brasil \\ brenoferreira2015@outlook.com
}

\author{
SOUZA PICANÇO, MARCELO \\ Professor Doutor \\ Instituto de Tecnologia da Universidade Federal do \\ Pará, PPGEC - FEC - GAEMA - ACGEO \\ Pará, Brasil \\ marcelosp@ufpa.br
}

\author{
GOMES-PIMENTEL, MAURÍLIO \\ Doutorando em Engenharia Civil \\ Instituto de Tecnologia da Universidade Federal do \\ Pará, PPGEC - FEC - GAEMA - ACGEO \\ Pará, Brasil \\ mauriliogpimentel@gmail.com
}

\author{
PALHETA LACERDA, FERNANDA \\ Mestranda em Engenharia Civil \\ Pará, FEC - GAEMA - ACGEO \\ Pará, Brasil \\ fefepalheta@gmail.com \\ SANTOS MARTINS, WALLYSON \\ Professor Mestre \\ Instituto Federal do Maranhão \\ Maranhão, Brasil \\ wallysonsmartins@gmail.com
}

Instituto de Tecnologia da Universidade Federal do

\section{RESUMO}

Projeções do crescimento populacional indicam que a população mundial crescerá 2 bilhões nos próximos 30 anos, aumentando a demanda de muitos recursos, como água potável. Estações de tratamento de água (ETA) são responsáveis por realizar a potabilização da água, gerando resíduo rico em aluminossilicatos, o lodo, prejudicial ao meio ambiente quando descartado. Uma solução ao descarte é aplicá-lo em sínteses geopoliméricas, como argamassas para reparo. Geopolímeros são materiais obtidos pela ativação alcalina de aluminossilicatos. Aqui produziu-se uma argamassa geopolimérica a base de lodo de ETA calcinado e caracterizou-se suas propriedades mecânicas, de absorção, retração e perda de massa. Os resultados indicaram alto aumento de resistência nas primeiras idades e a perda de massa não correlacionou com a retração, a absorção diminuiu aumentando-se as idades. O uso do resíduo é promissor, dado seu bom desempenho em geopolímeros e sua importância ecológica quando incorporado na indústria.

Palavras-chave: Geopolímero, Ativação alcalina, Reaproveitamento de resíduos, Argamassas de reparo, Cimento ecológico.

\begin{abstract}
Projections of population growth indicate that the world population will grow by 2 billion over the next 30 years, increasing the demand for many resources, such as drinking water. Water treatment station (WTS) are responsible for making the water potable, generating waste rich in aluminosilicates, the sludge, harmful to the environment when disposed of. One solution to disposal is to apply it to geopolymeric syntheses, such as mortars for repair. Geopolymers are materials obtained by the alkaline activation of aluminosilicates. Here, a geopolymeric mortar based on calcined WTS sludge was produced and its mechanical properties, absorption, shrinkage and loss of mass were characterized. The results indicated a high increase in strength in the early ages and the loss of mass did not correlate with the retraction, the absorption decreased with increasing ages. The use of the waste is promising, given its good performance in geopolymers and its ecological importance when incorporated in the industry. Keywords: Geopolymer, Alkaline Activation, Waste Reuse, Repair Mortars, Ecological Cement.
\end{abstract}




\section{INTRODUÇÃO}

O crescimento populacional das cidades tem provocado grandes demandas de recursos, dentre esses, a necessidade de maior volume de água potável (ASHOORI; DZOMBAK; SMALL, 2017). De acordo com a Organização das Nações Unidas (ONU), a população deve aumentar em cerca de 2 bilhões de pessoas em 30 anos e, em 2100, a população mundial deve atingir 11 bilhões de pessoas (UNITED NATIONS, 2019), aumentando a demanda de água e de serviços de potabilização desse recurso. As estações de tratamento de água (ETA) são responsáveis por realizar o beneficiamento da água e torná-la potável para a população a partir de vários processos físicos e químicos, envolvendo etapas como: coagulação, floculação, decantação, filtração e desinfecção (TARTARI et al., 2011; AHMAD et al., 2016). No entanto, esses processos produzem um resíduo prejudicial ao meio ambiente: o lodo de ETA. A grande dificuldade encontrada por empresas e instituições em dar um destino adequado a esse material tem se tornado evidente ao redor do mundo todo, principalmente nos países em desenvolvimento, fazendo com que esse resíduo seja descartado em ambientes inapropriados (AHMAD et al., 2016). A principal consequência desse descarte, que geralmente ocorre em aterros sanitários, lagos ou rios (TEIXEIRA et al., 2011; SANTOS et al., 2019), é o impacto negativo que isso ocasiona no meio ambiente, uma vez que o lodo de ETA é formado por compostos metálicos, silicosos e orgânicos (TARTARI et al., 2011; FERONE et al., 2019), prejudicando o lençol freático e a vida de diversas espécies.

No Brasil, há mais de 7000 estações de tratamento de água (ACHON; BARROSO; CORDEIRO, 2013) e, embora não se tenha dados precisos acerca da produção anual de lodo de ETA, estima-se que uma estação produza cerca de 100.000 toneladas de lodo por ano (AHMAD; ALAM, 2016). Em escala global, é estimado uma produção de cerca de 10.000 toneladas de lodo por dia (HAGARE, 1997). Desse modo, observa-se uma grande disponibilidade desse material e uma baixa demanda, sendo necessária a adoção de práticas sustentáveis a fim de atribuir uma função social e econômica ao resíduo. A incorporação do lodo de ETA na construção civil é uma alternativa inteligente e viável a sua destinação final. Diversos estudos investigam o uso do lodo na confecção de cimentos geopoliméricos, utilizados na produção de cerâmicas (SANTOS; MELO FILHO; MANZATO, 2018) ou argamassas formadas a partir da ativação alcalina (NIMWINYA et al., 2016; GERALDO; FERNANDES; CAMARINI, 2017; SANTOS et al., 2019).

Geopolímeros são aglutinantes sintetizados a partir da adição de um precursor, composto por aluminossilicatos amorfos, e um ativador alcalino (PROVIS; VAN DEVENTER, 2019). A reação geopolimérica consiste na dissolução dos aluminossilicatos em meio alcalino, essa dissolução dará inicio ao processo de rearranjo das espécies dissolvidas que provocará a gel nucleação desses componentes de silício e alumínio, formando o gel geopolimérico, que irá se desenvolver e endurecer, sendo o principal responsável pelas propriedades mecânicas do geopolímero (BERNAL et al., 2014; PROVIS; VAN DEVENTER, 2019). O aumento progressivo de pesquisas acerca do uso do geopolímero na construção civil se explica pela grande versatilidade desse aglomerante, possuindo boas propriedades como alta resistência mecânica e ao fogo, menos suscetível ao ataque de agentes agressivos e elevada durabilidade (AGUIRREGUERRERO; ROBAYO-SALAZAR; DE GUTIÉRREZ, 2017; ZHANG et al., 2018), sendo uma ótima opção na produção de concretos ou materiais para reparo de estruturas.

A deterioração do concreto devido à corrosão da armadura é uma das principais patologias recorrentes nas construções civis, principalmente em ambientes expostos a uma grande concentração de íons cloreto, pois a corrosão provoca a expansibilidade do aço, resultando em fissuras e trincas no concreto (AHMAD, 2003). Diante disso, torna-se necessário a utilização de materiais para reparo com boas propriedades mecânicas e duráveis.

Argamassas geopoliméricas são uma alternativa interessante para essa aplicação, dada sua ótima performance em testes de desempenho no reparo de estruturas de concreto, obtendo resultados aproximados ou maiores do que produtos convencionais utilizados no mercado (PACHECO-TORGAL et al., 2012; FAHIM HUSEIEN et al., 2017). Argamassas geopoliméricas também mostraram um grande potencial para reparo de pavimento (ALANAZI et al., 2016), para utilização como grautes em recuperação de estruturas de concreto (ZHANG et al., 2019) e até mesmo para aplicações em estruturas sujeitas a ataques ácidos (CHERKI EL IDRISSI, 2019).

Para a síntese dos geopolímeros, são utilizados materiais com altos teores de aluminosilicatos, como: metacaullim, cinzas volantes e escória (CHERKI EL IDRISSI, 2019). O resíduo resultante do processo de tratamento de água é um material rico em aluminosilicatos que, quando calcinado, se torna amorfo, confirmando o potencial como precursor de geopolímeros (WAIJAREAN; ASAVAPISIT; SOMBATSOMPOP, 2014). Nesse contexto, a utilização do lodo de ETA em sínteses geopoliméricas demonstra ser coerente e ecologicamente correta. Portanto, esse trabalho objetiva produzir uma argamassa geopolimérica a base de lodo de ETA calcinado para reparo em estruturas de concreto, a fim de caracterizar suas propriedades mecânicas, de absorção, retração e perda de massa, além de comparar os resultados obtidos com parâmetros internacionais para uma argamassa de reparo, observando o atendimento aos requisitos mínimos desse produto. 


\section{MATERIAIS E MÉTODOS}

\subsection{Materiais}

Nesse estudo foi utilizado como fonte de aluminossilicato para a síntese do material um metacaulim com massa específica de $2200 \mathrm{~kg} / \mathrm{m}^{3}$ e lodo de ETA calcinado com massa específica de $2710 \mathrm{~kg} / \mathrm{m}^{3}$. A análise de fluorescência de raios X do lodo de ETA apresenta uma quantidade de silício e alumínio menor quando comparada com o metacaulim (Tabela 1), no entanto, essas composições são as esperadas quando comparadas com a de outros materiais avaliados na literatura (GERALDO; FERNANDES; CAMARINI, 2017). Além desses materiais foram utilizados um silicato de sódio alcalino $\left(\mathrm{Na}_{2} \mathrm{SiO}_{3}\right)$ com $32 \%$ de $\mathrm{SiO}_{2}$ e $14 \%$ de $\mathrm{Na}_{2} \mathrm{O}$, apresentando um módulo de sílica ( $\left.\mathrm{razão} \mathrm{molar}^{\mathrm{SiO}} / \mathrm{Na}_{2} \mathrm{O}\right)$ de 2,26 e densidade a $25^{\circ} \mathrm{C}$ de $1560 \mathrm{~kg} / \mathrm{m}^{3}$. Foi também empregado um hidróxido de sódio em escama $(\mathrm{NaOH})$ com $98 \%$ de pureza, água potável com pH 6,0 e uma areia de origem quartzosa com massa específica de $2650 \mathrm{~kg} / \mathrm{m}^{3}$.

Tabela 1 - Composição química dos materiais em (\%) obtidos por FRX. PF é perda ao fogo

\begin{tabular}{l|c|c|c|c|c|c|c|c|c|c}
\multicolumn{1}{c|}{ Material } & $\mathrm{SiO}_{2}$ & $\mathrm{Al}_{2} \mathrm{O}_{3}$ & $\mathrm{Fe}_{2} \mathrm{O}_{3}$ & $\mathrm{MgO}$ & $\mathrm{CaO}$ & $\mathrm{Na}_{2} \mathrm{O}$ & $\mathrm{K}_{2} \mathrm{O}$ & $\mathrm{TiO}_{2}$ & $\mathrm{P}_{2} \mathrm{O}_{5}$ & $\mathrm{PF}$ \\
\hline Lodo de ETA & 27,90 & 24,70 & 13,50 & 0,60 & 0,30 & - & 0,90 & 0,60 & 0,60 & 29,90 \\
\hline Metacaulim & 51,54 & 40,50 & 2,80 & - & - & 0,08 & 0,18 & - & - & 2,62 \\
\hline
\end{tabular}

O lodo de ETA utilizado na produção da argamassa geopolimérica foi coletado da Estação de Tratamento de Água do Bolonha, localizada na cidade de Belém-PA. O sistema de captação utiliza a água proveniente do lago Bolonha, que é alimentado pelo Rio Guamá. O resíduo in natura encontrava-se totalmente saturado, portanto, foi necessário realizar um processo de secagem. $\mathrm{O}$ material foi homogeneizado e submetido à secagem em estufa à temperatura de $100 \pm 5^{\circ} \mathrm{C}$ por 72h. Em seguida, o material foi submetido ao processo de moagem no moinho de bolas horizontal por 5 horas para garantir uma boa finura ao resíduo, com uma proporção de $5 \mathrm{~kg}$ de bolas para $1 \mathrm{~kg}$ de lodo, sendo $1 / 3$ de bolas de alumina com diâmetro de $20 \mathrm{~mm}$ e $2 / 3$ de bolas com $12 \mathrm{~mm}$ de diâmetro, conforme a metodologia empregada por POUEY, 2006. Com o material devidamente fino foram realizados ensaios de termogravimetria para verificar os principais eventos térmicos do material e a proporção de caliníta presente no material e difração de raio X para análise mineralógica do minerais presentes no resíduo antes da calcinação. Posteriormente, o material foi calcinado em uma mufla por 2 horas a uma temperatura de $800^{\circ} \mathrm{C}$, aquecendo junto à mufla e resfriado à temperatura ambiente. Essa temperatura se justifica pois o material se encontra mais amorfo e proprício para atuar como precursor na reação geopolimérica, em temperaturas menores e maiores que essa o resíduo se encontra parcialmente cristalino. Por fim, o lodo foi moído novamente por 2 horas no moinho de bolas para a desfragmentação dos torrões formados devido à calcinação, com proporção de $10 \mathrm{~kg}$ de bolas para $1 \mathrm{~kg}$ de material, sendo $2 / 3$ de bolas grandes e $1 / 3$ de bolas pequenas.

Para caracterizar o lodo de ETA, primeiramente foi realizado uma análise termogravimétrica de 0 à $1000^{\circ} \mathrm{C}$ sob atmosfera de gás nitrogênio, a temperatura ambiente foi de $25^{\circ} \mathrm{C} \pm 2{ }^{\circ} \mathrm{C}$ e foi utilizada uma massa de $8,75 \mathrm{mg}$. A taxa de aquecimento foi de $10^{\circ} \mathrm{C} / \mathrm{min}$. Além disso, foi realizada análise mineralógica dos materiais por difração de raios $\mathrm{X}$ (DRX), em um difratômetro de feixe divergente equipado com um goniômetro $\theta-\theta$, um tubo de raios-X de $\mathrm{Cu}$ com radiação de $\mathrm{Cu}(\mathrm{K} \alpha 1=1,540598 \AA$ ) e um filtro de $\mathrm{Ni} \mathrm{K} \beta$. As condições do instrumento foram as seguintes: $40 \mathrm{kV}$ e 40 $\mathrm{mA}$; fenda Soller de $2,5^{\circ}$ (feixe incidente e refratado); faixa angular (20) de $5^{\circ}$ a $70^{\circ}$. A coleta dos difratogramas foi realizada com passo angular de $0,02^{\circ}$ e tempo por passo de $0,5 \mathrm{~s}^{\circ}$, fenda divergente de $0,6 \mathrm{~mm}$. O ensaio de granulometria foi feito por difração a laser, o ultrassom foi de 60s, a medida de 60/60/4 e as concentrações de material foram imersas em água.

A análise mineralógica do lodo de ETA in natura e calcinado à $800^{\circ} \mathrm{C}$ (Figura $1 \mathrm{~B}$ ) evidencia a formação de um material amorfo devido ao processo de calcinação, caracterizado pelo halo amorfo no lodo à $800{ }^{\circ} \mathrm{C}$. No DRX do lodo in natura é evidenciado um material cristalino, apresentando fases de minerais de quartzo $\left(\mathrm{SiO}_{2}\right)$ e caulinita $\left(\mathrm{Al}_{2} \mathrm{Si}_{2} \mathrm{O}_{5}(\mathrm{OH})_{4}\right)$, resultado coerente com outras caracterizações disponíveis na literatura para o mesmo tipo de resíduo (TARTARI et al., 2011; CARLOS; PINHEIRO, 2014). A análise de Rietveld evidenciou a presença de 57,7\% de caulinita.

O comportamento térmico do resíduo in natura seco foi observado por meio do ensaio de termogravimetria. A análise (Figura 1A) mostrou 4 eventos térmicos bem característicos, similar ao comportamento térmico de materiais argilosos (ARSENOVIĆ et al., 2014; ARAB; ARAÚJO; PEJON, 2015; SANTOS et al., 2016). O primeiro evento foi observado entre entre 50 e $100{ }^{\circ} \mathrm{C}$, justificado pela perda de água adsorvida, representando uma redução de massa em torno de $7 \%$. O segundo evento ocorreu na faixa entre 300 e $400{ }^{\circ} \mathrm{C}$ e pode ser explicado pela desidroxilação de hidróxidos e perda de matéria orgânica, ocorrendo perda de massa de aproximadamente $17 \%$. No terceiro fenômeno térmico, foi observado um pico entre 450 e $500{ }^{\circ} \mathrm{C}$, relacionado à desidroxilação da estrutura da caulinítica, havendo perda de $7,5 \%$, comprovando a presença de cauliníta já evidenciada pela análise de Rietveld, apresentando cerca de 54,7\% de cauliníta no material. No último evento, caracterizado por um pico em $920^{\circ} \mathrm{C}$, a perda de massa torna-se constante e próxima de 
zero. Por volta dessa temperatura, inicia-se o processo de recristalização do material, explicado pela quebra da estrutura metacaulinítica para a formação de fases cristalinas como $\gamma-\mathrm{Al}_{2} \mathrm{O}_{3}$ ou Mulita (BALEK; MURAT, 1996; ARSENOVIĆ et al., 2014).

A granulometria do lodo de ETA calcinado (Figura 1C), realizada por meio da granulometria a laser, mostrou-se muito próxima ao do metacaulim, possuindo $90 \%$ das partículas inferior a 79,43 $\mu \mathrm{m}$ e um diâmetro médio de $25,12 \mu \mathrm{m}$, enquanto o metacaulim possui $90 \%$ das partículas inferior a $62,2 \mu \mathrm{m}$ e diâmetro médio de $24,80 \mu \mathrm{m}$.
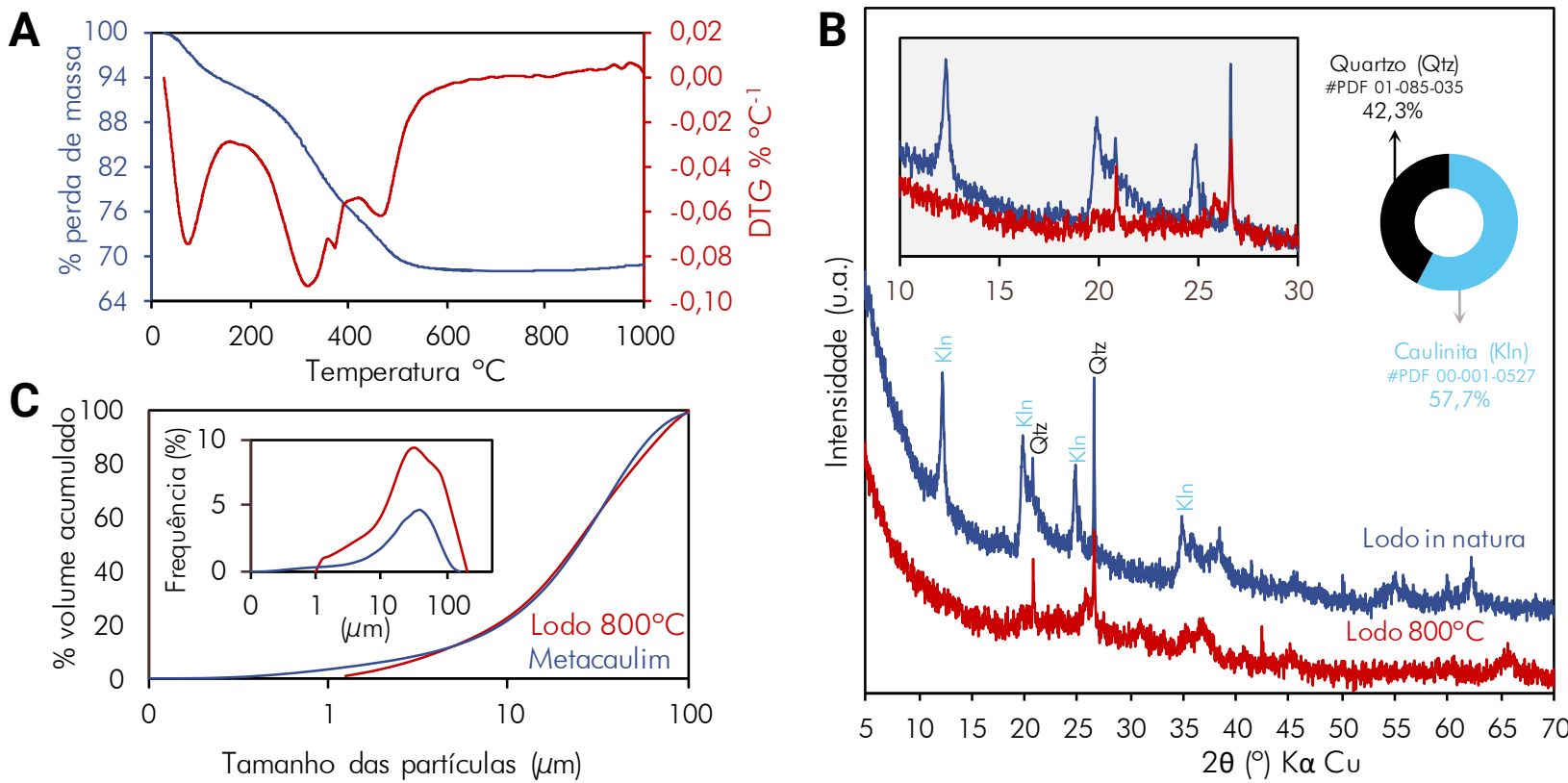

Figura 1: Comportamento térmico, mineralógico e granulometria a laser. (A) Análise termogravimétrica e a derivada da termogravimetria do lodo de ETA. (B) Análise mineralógica do lodo in natura e calcinado à $800{ }^{\circ} \mathrm{C}$ e apresentação da análise de Rietveld, evidenciando a presença de 57,7\% de caulinita. (C) Análise granulométrica por granulometria a laser do metacaulim e lodo de ETA

Foi realizado o DRX de uma pasta antes e depois da síntese geopolimérica com a mesma proporção dos precursores utilizados na argamassa, a fim de se detectar mais claramente indícios da ocorrência de reação geopolimérica. A presença de halos amorfos na pós-síntese indica uma reação de geopolimerização, pois o material apresentou estrutura amorfa quase completa, com exceção das fases cristalinas como o quartzo, que continuam presentes na reação mesmo após a síntese (WANG; LI; YAN, 2005). Além disso, ao comparar os padrões antes e depois da síntese, observou-se que houve uma mudança no halo amorfo no material após a síntese (Figura 2), essa mudança sugere a formação de géis geopoliméricos (KENNE DIFFO et al., 2015; LAHOTI et al., 2018).

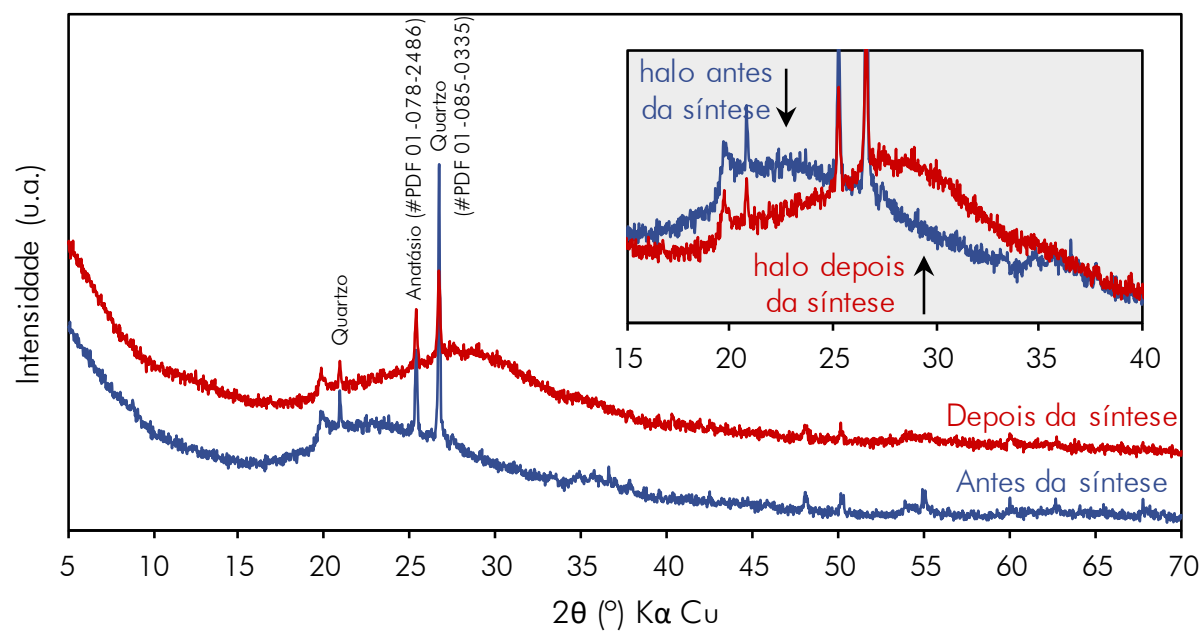

Figura 2: Análise mineralógica da pasta geopolimérica a base de lodo de ETA e metacaulim antes e depois da síntese geopolimérica 


\subsection{Métodos}

As argamassas foram misturadas utilizando um traço de precursor/agregado miúdo de 1:3, sendo 70\% do precursor composto por metacaulim e $30 \%$ por lodo de ETA calcinado. A proporção em massa dos materiais em função da quantidade do metacaulim e do lodo $(\mathrm{MK}+$ Lodo $=1)$ está representada na Tabela 2.

Tabela 2 - Proporção dos materiais constituintes da argamassa

\begin{tabular}{c|c|c|c|c|c}
\hline \multicolumn{2}{|c|}{ Precursor (1) } & \multicolumn{2}{|c|}{ Ativador Alcalino } & \multirow{2}{*}{ Areia } & \multirow{2}{*}{ Água } \\
\cline { 1 - 3 } Metacaulim & Lodo de ETA Calcinado & $\mathrm{Na}_{2} \mathrm{SiO}_{3}$ & $\mathrm{NaOH}$ & & \\
\hline 0,7 & 0,3 & 0,66 & 0,08 & 3,00 & 0,40 \\
\hline
\end{tabular}

A areia utilizada na mistura foi seca por 24 horas em estufa à $100{ }^{\circ} \mathrm{C} \pm 5{ }^{\circ} \mathrm{C}$. Os materiais foram devidamente pesados em uma balança de precisão 0,01g e organizados em vasilhames plásticos. Primeiramente foi misturado a água e o $\mathrm{NaOH}$ na argamassadeira em velocidade baixa por 5 minutos em um misturador mecânico com capacidade de 5 litros e velocidade de rotação de $140 \pm 5 \mathrm{Rr} / \mathrm{min}$, misturando em seguida o $\mathrm{Na}_{2} \mathrm{SiO}_{3}$ por mais 4 minutos. Após isso, o lodo de ETA e o metacaulim foram adicionados à mistura por 1 minuto em velocidade baixa mais 1 minuto em velocidade alta, utilizando o processo de mistura conforme NBR 16541 (ABNT, 2016). A areia foi misturada em seguida por 3 minutos em velocidade alta. Durante o processo foi observado falta de trabalhabilidade do material para realizar a moldagem dos corpos de prova para uma relação água/precursor de 0,34 , sendo necessario adição de mais água (a Tabela 2 já apresenta o valor final da relação água/precursor utilizado). Após a mistura, as argamassas foram moldadas em moldes prismáticos $4 \mathrm{~cm}$ x $4 \mathrm{~cm}$ x $16 \mathrm{~cm}$ e adensados em uma mesa de queda com altura de queda de 12,5 mm para retirada de ar aprisionado. Foram moldados 9 corpos de prova prismáticos para a realização dos ensaios de compressão, tração e absorção de água, sendo 3 amostras para cada idade de ensaio (3, 7 e 28 dias) e 3 corpos corpos de prova no formato 2,5 $\mathrm{cm} \times 2,5 \mathrm{~cm}$ × $25 \mathrm{~cm}$ para o ensaio de retração linear. As amostras foram curadas em uma câmara climática com temperatura de $30 \pm 2{ }^{\circ} \mathrm{C}$ e umidade relativa de $60 \%$ até os dias de seus respectivos ensaios.

A tração das argamassas geopoliméricas a base de lodo de ETA foi avaliada por meio do ensaio de flexão nos corpos de prova $4 \mathrm{~cm} \times 4 \mathrm{~cm} \times 16 \mathrm{~cm}$ por meio do teste de 3 pontos em uma velocidade de deslocamento da prensa $0,1 \mathrm{~mm} / \mathrm{min}$. O ensaio de compressão foi realizado nas peças residuais obtidas a partir do teste de flexão, utilizando barra metálica de $4 \mathrm{~cm}$ x $4 \mathrm{~cm}$ na base do fragmento e na parte superior, onde ocorrerá a aplicação da carga axial, com velocidade de 0,5 mm/min, de acordo com normatização brasileira NBR 13279 (ABNT, 2005).

A retração linear foi avaliada durante 28 dias consecutivos em um relógio comparador de precisão de $0,001 \mathrm{~mm}$. As amostras estavam armazenadas em uma câmara climática com condições de temperatura de $30 \pm 2{ }^{\circ} \mathrm{C}$ e umidade relativa de $60 \%$.

A análise de absorção foi realizada utilizando a NBR 9778 (ABNT, 2011). As amostras utilizadas eram provenientes dos fragmentos residuais dos corpos de prova submetidos à ruptura por flexão. Os ensaios foram feitos à cada realização do ensaio de flexão, para as idades de 3, 7 e 28 dias. As amostras foram imersas por 48 horas após cada ensaio e fervidas por 1 hora para retiradas de bolhas de ar. Após fervura, foi esperado o tempo de resfriamento para aquisição dos dados. Foram obtidos dados para determinação da absorção de água, índice de vazios e densidade aparente.

Os dados foram analisados quanto a sua normalidade e homocedasticidade, os ensaios de resistência à compressão e à flexão, absorção de água, índice de vazios e densidade aparente foram analisados utilizando-se análise de variância de uma via complementado pelo teste de Tukey. Já a retração e a taxa de perda de massa das argamassas foram analisadas utilizando-se ANOVA de Kruskal-Wallis, com fator de correção de Bonferroni por não apresentarem homogeneidade nas variâncias e conterem mais de duas condições experimentais, além disso a relação entre a perda de massa e a retração foi realizada por meio de regressão linear simples. Foram consideradas diferenças significativas quando $\mathrm{P}<0,05$.

\section{RESULTADOS E DISCUSSÃO}

\subsection{Propriedades mecânicas}

Os resultados da avaliação da resistência à tração na argamassa geopolimérica a base de lodo de ETA (Figura 3B) indicam um bom desempenho desse material sob solicitações de tração. Esses resultados são compatíveis com argamassas geopoliméricas a base de metacaulim ou cinzas volantes (KARIM et al., 2013; GÖRHAN; KÜRKLÜ, 2014), que são precursores convencionais para geopolímero (DAVIDOVITS et al., 1999). No entanto, esses resultados 
são maiores quando comparados com argamassas que utilizam lodo de ETA como parte do precursor (GERALDO; FERNANDES; CAMARINI, 2017). Possivelmente, o tratamento térmico favoreceu as reações de geopolimerização, tornando o material mais reativo (GERALDO; FERNANDES; CAMARINI, 2017). Aos 7 e 28 dias, a argamassa não apresentou evoluções significativas na resistência, o que possivelmente se deve ao fato de a argamassa já ter alcançado grande parte de sua resistência nos primeiros dias (SUKSIRIPATTANAPONG et al., 2015). O desenvolvimento de boas resistências à tração nas argamassas geopoliméricas com lodo de ETA corroboram para a sua utilização em argamassas de reparo. Esses resultados podem ser ainda melhores, variando-se a concentração molar da solução ativadora, incorporando sílica ou variando a temperatura de cura (ZHANG et al., 2018).

A resistência à compressão para as idades iniciais apresentou uma alta taxa de desenvolvimento de resistência, atingindo uma média cerca de $22 \mathrm{MPa}$ já para o terceiro dia (Figura 3A). De acordo com a análise estatística, as respostas na resistência à compressão e na flexão não aumentaram com o aumento da idade, atingindo sua resistência máxima logo nas primeiras idades. Para argamassas de reparo, obter sua resistência máxima logo nas primeiras idades é um fator importante para a sua finalidade (FAHIM HUSEIEN et al., 2017), uma vez que o curto tempo disponível para a execução do serviço demanda de uma alta performance inicial do material. A argamassa, no sétimo dia, cumpre o requisito de resistência à compressão para materiais de reparo em estruturas de concreto classe R3 ( $\geq 25 \mathrm{MPa}$ ), segundo a Norma Europeia EN 1504 (EN 1504-3, 2006), caracterizando-a como material de reparo destinado a concretos estruturais de baixa resistência. A ocorrência da reação geopolimérica pôde ser constatada a partir do endurecimento do material ocorrida em 24 horas e no crescimento contínuo de sua resistência para as idades testadas. O lodo de ETA calcinado a $800{ }^{\circ} \mathrm{C}$ mostrou ser muito eficiente como precursor, visto que os aluminossilicatos reativos, formados devido à calcinação, podem ter participado da síntese, uma vez que a dissolução do Si e do Al da estrutura aluminossilicato, sob condições alcalinas, provoca um desequilíbrio de íons do Al, compensado depois pelos cátions $\mathrm{Na}^{+}$provenientes do $\mathrm{NaOH}$ e $\mathrm{Na}_{2} \mathrm{SiO}_{3}$, formando redes de aluminossilicatos estáveis (ZHANG; MACKENZIE; BROWN, 2009; WAIJAREAN; ASAVAPISIT; SOMBATSOMPOP, 2014) que depois irão se solidificar e ganhar resistência até uma determinada idade, como ocorreu na argamassa estudada neste artigo. A escolha pela temperatura de calcinação do lodo de ETA à $800{ }^{\circ} \mathrm{C}$ se justifica pelo maior grau de compostos amorfos no material, sendo mais suscetível à reação geopolimérica. Alguns estudos na literatura avaliaram o efeito da variação da temperatura de calcinação do lodo na reação geopolimérica (WAIJAREAN; ASAVAPISIT; SOMBATSOMPOP, 2014) e do uso de lodo não calcinado (GERALDO; FERNANDES; CAMARINI, 2017), concluindo que a temperatura ideal de calcinação situa-se por volta de $800{ }^{\circ} \mathrm{C}$, pois para temperaturas maiores que essa inicia-se o processo de recristalização do material devido a formação de mulita (BALEK; MURAT, 1996; BARBOSA; MACKENZIE, 2003; ARSENOVIĆ et al., 2014; CARLOS; PINHEIRO, 2014), um componente menos reativo, e em temperaturas menores, algumas reações químicas como combustão da matéria orgânica para temperaturas em torno de $400{ }^{\circ} \mathrm{C}$ e desidroxilação da estrutura da caulinita podem não ter sido finalizados completamente (CARLOS; PINHEIRO, 2014), prejudicando a reação geopolimérica e comprometendo a resistência do produto final.
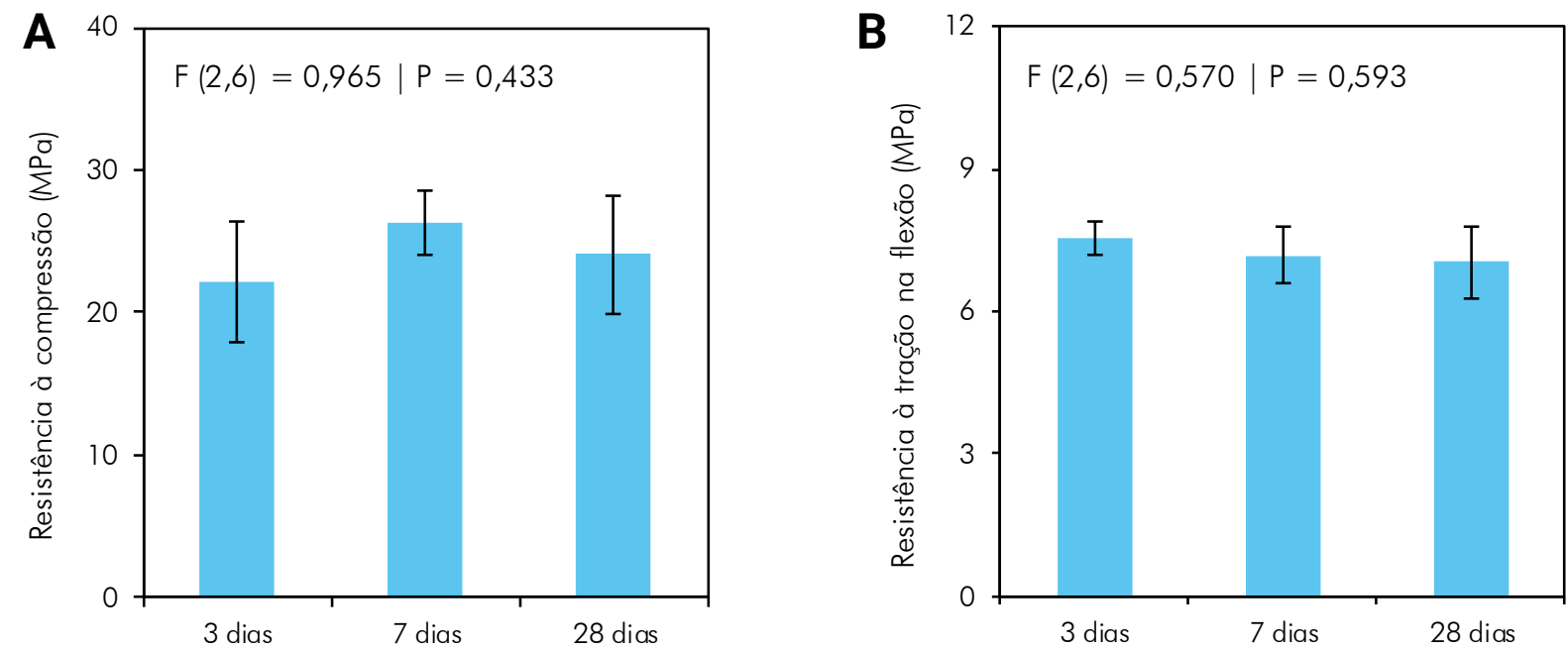

Figura 3: Ensaios de resistência mecânica. (A) Resistência à compressão para idades de 3, 7 e 28 dias. (B) Resistência à tração na flexão para idades de 3, 7 e 28 dias. Valores representados como média \pm desvio padrão. 


\subsection{Retração linear e perda de massa}

A avaliação da retração linear das argamassas foi avaliada juntamente à perda de massa do material durante 28 dias (Figura 4). Constatou-se que a perda de massa é significativa com o aumento da idade, no entanto, esta perda não está associada à retração, uma vez que, a partir do terceiro dia, a retração linear deixa de ser relevante, segundo análise estatística, não havendo, portanto, correlação entre essas duas propriedades. Isso sugere que a massa perdida é proveniente apenas da perda de umidade e água livre do geopolímero, uma vez que essa água não participa da formação do gel geopolimérico (J. L. PROVIS, 2009; MASTALI et al., 2018), atuando apenas como um meio solúvel para a solubilização dos componentes alcalinos da mistura, diferente das misturas à base de cimento Portland, onde a água participa diretamente da reação de hidratação (AÏTCIN, 2016). A retração do material se mostrou relevante até o segundo dia, não havendo variações lineares tão significativas após essa idade. O encolhimento no estado endurecido de materiais geopoliméricos ocorre de duas formas: autógena por autodessecação e por secagem (YANG; ZHU; ZHANG, 2017). O encolhimento autógeno por autodessecação é caracterizada pela geopolimerização contínua do material que expulsa a água dos poros capilares, ocorrendo pressões desse fluido nos poros do aglomerante (LEE; JANG; LEE, 2014), enquanto que por secagem significa a evaporação da água da redes de poros do aglomerante, gerando tensão capilar no material (YANG; ZHU; ZHANG, 2017). Na retração avaliada, constatou-se um aumento brusco da retração nos dois primeiros dias, o que caracteriza uma retração por secagem, devido à perda rápida de água da superfície após desmoldagem (YANG; ZHU; ZHANG, 2017). De acordo com a Norma Europeia EN 1504, o produto se enquadra nos pré-requisitos de materiais para reparo por possuir uma retração $\leq 0,1 \%$.

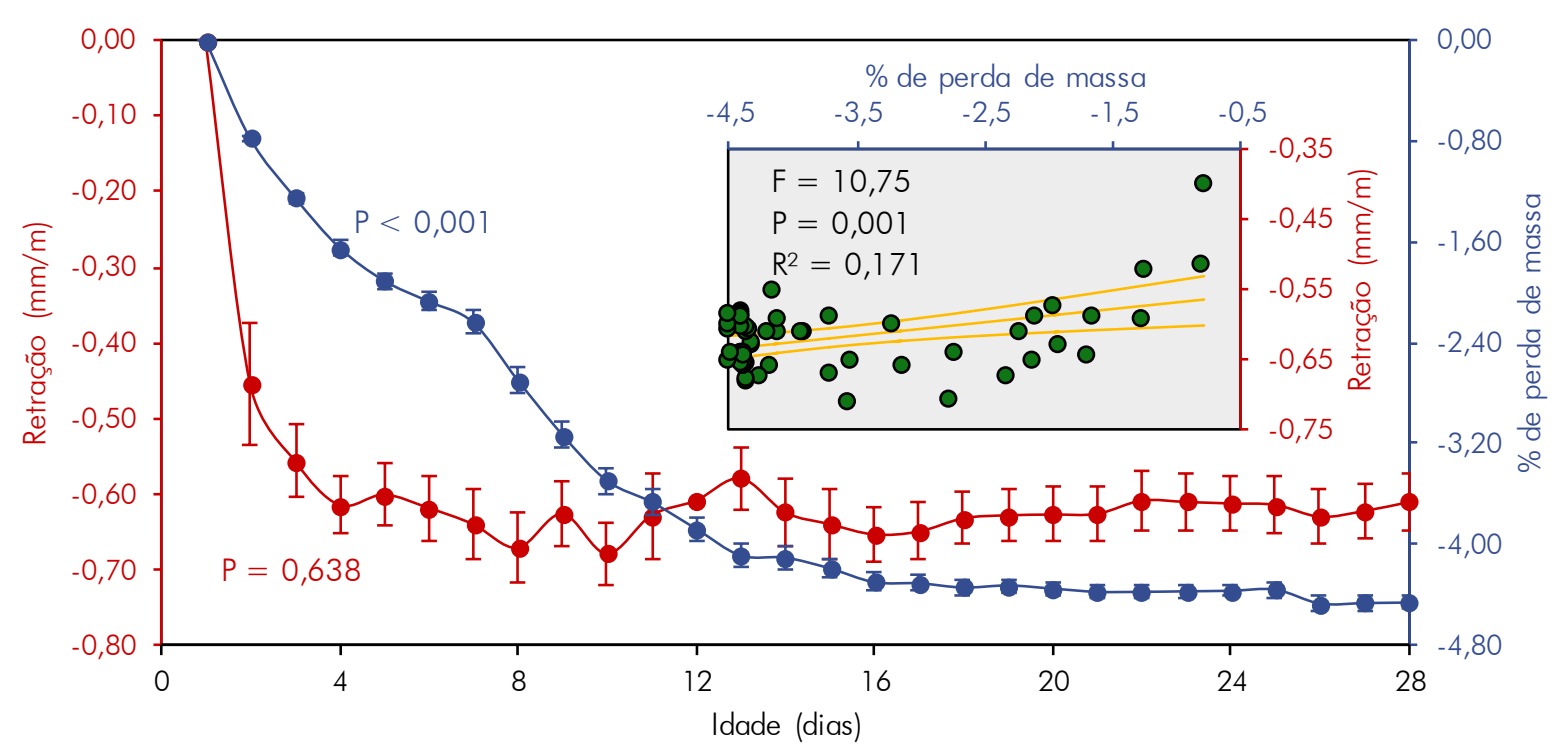

Figura 4: Retração linear da argamassa ao longo do tempo. Valores representados como média \pm desvio padrão.

Por conta da retração não estar associada à perda de água do material, o uso dessa argamassa em ambientes sujeitos a temperaturas mais elevadas é muito proprício, visto que algumas patologias que ocorrem em materiais convencionais, como no cimento Portland, podem ser observadas quando o material é submetido à cura em ambientes sob altas temperaturas, ocorrendo um processo de retração brusca, associado ao aparecimento de fissuras por retração devido à perda de água que ocorre na estrutura cimentícia (C-S-H). Portanto, uma vez que a água não faz parte da estrutura geopolimérica, essa água livre pode evaporar sem prejuízo da variação volumétrica do material, mantendo sua estabilidade.

\subsection{Absorção, índice de vazios e densidade aparente.}

Os resultados do ensaio de absorção demonstraram coerência quando comparado ao índice de vazios da amostra (Figura 5A e 5B). Entre as idades de 3 e 7 dias não houve diferenças significativas tanto para a absorção quanto para o índice de vazios, mas quando comparados a idade de 28 dias, a absorção e o índice de vazios diminuíram, portanto, pode-se assumir que o aumento das idades de cura provoca a diminuição do índice de vazios e absorção de água. A temperatura de cura interfere diretamente na absorção de água, como avaliado por alguns estudos (ZHANG et al., 2018), mas como as amostras foram submetidas à temperatura de cura constante, isso não foi uma variável para esse estudo. A 
diminuição do índice de vazios e absorção pode ser explicado pela formação de produtos geopoliméricos decorrentes da síntese por álcali ativação dos aluminossilicatos, diminuindo assim o número de vazios e a porosidade da amostra. Não houve mudanças significativas na densidade relativa para o período de 28 dias, uma vez que P>0,05 (Figura 5C), sendo coerente com o esperado, uma vez que não houve variações representativas no volume, como mostrado no ensaio de retração linear.
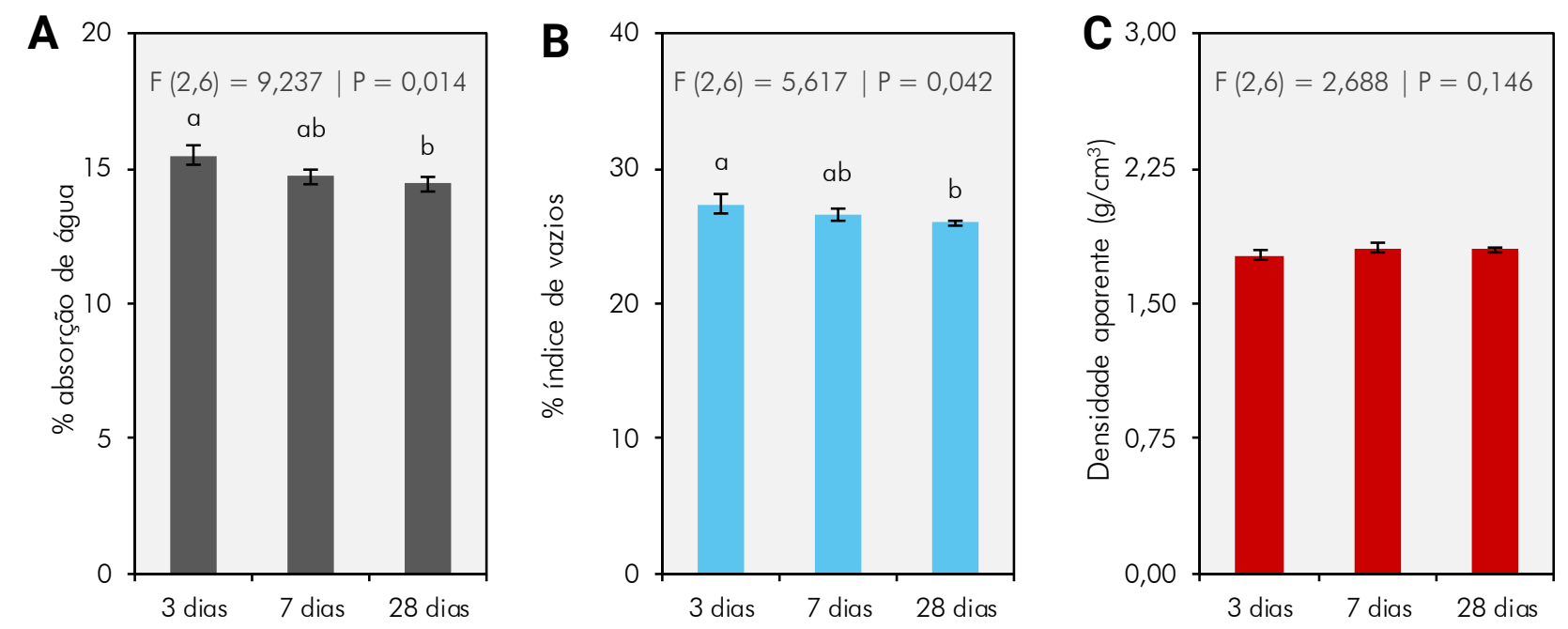

Figura 5: Resultados do ensaio de absorção por imersão para idades de 3, 7 e 28 dias. (A) A absorção de água. (B) Índice de vazios. (C) Densidade aparente. Valores representados como média \pm desvio padrão. Letras minúsculas distintas indicam diferença estatística quando comparado entre as idades para a mesma variável.

Alguns trabalhos presentes na literatura evidenciam que materiais geopoliméricos apresentam menor porosidade quando comparado com materiais formados por cimento Portland (BERNAL; MEJÍA DE GUTIÉRREZ; PROVIS, 2012; ZHU et al., 2014), resultando no ganho de algumas propriedades muito importantes para materiais destinados para a aplicação como reparo, como a redução de permeabilidade ao cloreto e agentes agressivos (AGUIRRE-GUERRERO et al., 2017), reduzindo a possibilidade de patologias provenientes de corrosão da armadura metálica. A menor porosidade do geopolímero pode ser explicada pela maior densidade da estrutura do gel geopolimérico (ISMAIL et al., 2013), dificultando a penetração de agentes maléficos.

\section{CONCLUSÕES}

Uma argamassa geopolimérica a base de lodo de ETA calcinado para reparo de estruturas de concreto foi avaliada neste estudo. Os resultados indicaram um bom desempenho do resíduo na síntese geopolimérica em formulações de argamassa formadas por metacaulim e lodo, confirmando a eficiência desse material como precursor em ativações alcalinas. Suas maiores resistências foram atingidas logo nas primeiras idades de cura e sua resistência à tração foi cerca de $30 \%$ da resistência à compressão, valor muito elevado quando comparado à produtos compostos por cimento Portland. A retração linear por secagem do material ocorreu até o segundo dia de idade de cura e sua perda de massa se manteve contínua, devido à perda de umidade. Isso indica que a utilização do material no reparo de estruturas de concreto pode ser muito eficiente, uma vez que a estabilidade volumétrica do material é fundamental para que o conserto da patologia seja eficaz. Em relação à absorção do material, houveram aumentos significativos para a absorção de água e índice de vazios entre as idades de 3 e 28 dias de cura, entretando sua densidade aparente manteve-se constante durante todo esse período. No entanto, embora ainda seja necessário mais estudos e investigações de determinadas propriedades, como aderência, resistência à cloretos e sufaltos, módulo de elásticidade e etc., para se garantir a total utilização desse material como reparador em estruturas de concreto, a argamassa geopolimérica estudada apresentou resultados muito promissores nos testes realizados, evidenciando que a utilização do resíduo do processo de tratamento de água é uma boa alternativa ao descarte em aterros sanitários e rios, além de representar um produto ecológico e eficente para a indústria da construção civil, fomentando a economia sustentável e contribuindo para um mundo mais limpo. 


\section{AGRADECIMENTOS}

Os autores agradecem à Pró-Reitoria de Pesquisa e Pós-Graduação (PROPESP) da UFPA pelo apoio financeiro através de bolsas de pesquisa, ao Laboratório de Materiais de Construção (LEMAC), locado no Laboratório de Engenharia Civil da UFPA, pelo fornecimento de equipamentos para a realização dos ensaios, ao Laboratório de Engenharia Química da UFPA (LEQ) pelo fornecimento do forno para a realização do tratamento térmico do material, ao Laboratório de Análise Térmica e Dielétrica do Programa de Pós-Graduação de Física da UFPA pela realização do ensaio de difração de raios X, ao Laboratório do Instituto de Geociências da UFPA pela realização da granulometria a laser e à Metacaulim do Brasil, empresa responsável pelo fornecimento do metacaulim utilizado na síntese.

\section{REFERÊNCIAS}

ABNT. NBR 9778 - Argamassa e concreto endurecidos -Determinação da absorção de água, índice de vazios e massa específica. Associação Brasileira de Normas Técnicas, 2011.

ABNT. ABNT NBR 16541 - Argamassa para assentamento e revestimento de paredes e tetos - Preparo da mistura para a realização de ensaiosAssociação Brasileira de Normas Técnicas, 2016.

ACHON, C. L.; BARROSO, M. M.; CORDEIRO, J. S. Resíduos de estações de tratamento de água e a ISO 24512: Desafio do saneamento brasileiro. Engenharia Sanitaria e Ambiental, v. 18, n. 2, p. 115-122, 2013.

AGUIRRE-GUERRERO, A. M.; ROBAYO-SALAZAR, R. A.; DE GUTIÉRREZ, R. M. A novel geopolymer application: Coatings to protect reinforced concrete against corrosion. Applied Clay Science, v. 135, p. 437-446, 2017. Disponível em: <http://dx.doi.org/10.1016/j.clay.2016.10.029>.

AHMAD, S. Reinforcement corrosion in concrete structures, its monitoring and service life prediction - A review. Cement and Concrete Composites, v. 25, n. 4- 5 SPEC, p. 459-471, 2003.

AHMAD, T. et al. Characterization of water treatment sludge and its reuse as coagulant. Journal of Environmental Management, v. 182, p. 606-611, 2016. Disponível em: 〈http://dx.doi.org/10.1016/j.jenvman.2016.08.010〉.

AHMAD, T.; AHMAD, K.; ALAM, M. Sustainable management of water treatment sludge through 3'R' concept. Journal of Cleaner Production, v. 124, p. 1-13, 2016. Disponível em: <http://dx.doi.org/10.1016/j.jclepro.2016.02.073>.

AÏTCIN, P. C. Portland cement. [s.1.] Elsevier Ltd, 2016.

ALANAZI, H. et al. Bond strength of PCC pavement repairs using metakaolin-based geopolymer mortar. Cement and Concrete Composites, v. 65, p. 75-82, 2016. Disponível em: 〈http://dx.doi.org/10.1016/j.cemconcomp.2015.10.009>.

ARAB, P. B.; ARAÚJO, T. P.; PEJON, O. J. Identification of clay minerals in mixtures subjected to differential thermal and thermogravimetry analyses and methylene blue adsorption tests. Applied Clay Science, v. 114, p. 133-140, 2015. Disponível em: <http://dx.doi.org/10.1016/j.clay.2015.05.020>.

ARSENOVIĆ, M. et al. Thermal and mineralogical characterization of loess heavy clays for potential use in brick industry. Thermochimica Acta, v. 580, p. 38-45, 2014.

ASHOORI, N.; DZOMBAK, D. A.; SMALL, M. J. Identifying water price and population criteria for meeting future urban water demand targets. Journal of Hydrology, v. 555, p. 547-556, 2017. Disponível em: <https://doi.org/10.1016/j.jhydrol.2017.10.047>.

ASSOCIAÇÃO BRASILEIRA DE NORMAS TÉCNICAS. NBR 13279 - Argamassa para assentamento e revestimento de paredes e tetos - Determinação da resistência à tração na flexão e à compressão. p. 2, 2005.

BALEK, V.; MURAT, M. The emanation thermal analysis of kaolinite clay minerals. Thermochimica Acta, v. 282283, n. SPEC. ISS., p. 385-397, 1996.

BARBOSA, V. F. F.; MACKENZIE, K. J. D. Thermal behaviour of inorganic geopolymers and composites derived from sodium polysialate. Materials Research Bulletin, v. 38, n. 2, p. 319-331, 2003. 
BERNAL, S. A. et al. Alkali Activated Materials. [s.l: s.n.]v. 13

BERNAL, S. A.; MEJÍA DE GUTIÉRREZ, R.; PROVIS, J. L. Engineering and durability properties of concretes based on alkali-activated granulated blast furnace slag/metakaolin blends. Construction and Building Materials, v. 33, p. 99-108, 2012. Disponível em: <http://dx.doi.org/10.1016/j.conbuildmat.2012.01.017〉.

CARLOS, B.; PINHEIRO, A. V.19 n.03. p. 204-211, 2014.

CHERKI EL IDRISSI, A. The development of a global mix design and analysis approach for alkali activated soil reinforcement grouts. European Journal of Environmental and Civil Engineering, v. 23, n. 5, p. 645-656, 2019. Disponível em: <https://doi.org/10.1080/19648189.2018.1519461>.

DAVIDOVITS, J. et al. Geopolymeric cement based on low cost geologic materials. Results from the european research project geocistem. Géopolymère '99 Proceedings, v. 2, n. November 2018, p. 83-96, 1999.

EN 1504-3. Products and systems for the protection and repair of concrete structures - Definitions, requirements, quality control and evaluation of conformity - Part 3: Structural and non-structural repair. European Standards, 2006.

FAHIM HUSEIEN, G. et al. Geopolymer mortars as sustainable repair material: A comprehensive review. Renewable and Sustainable Energy Reviews, v. 80, n. February 2016, p. 54-74, 2017. Disponível em: <http://dx.doi.org/10.1016/j.rser.2017.05.076>.

FERONE, C. et al. Sustainable management of water potabilization sludge by means of geopolymers production. Journal of Cleaner Production, v. 229, p. 1-9, 2019.

GERALDO, R. H.; FERNANDES, L. F. R.; CAMARINI, G. Water treatment sludge and rice husk ash to sustainable geopolymer production. Journal of Cleaner Production, v. 149, p. 146-155, 2017. Disponível em: <http://dx.doi.org/10.1016/j.jclepro.2017.02.076>.

GÖRHAN, G.; KÜRKLÜ, G. The influence of the NaOH solution on the properties of the fly ash-based geopolymer mortar cured at different temperatures. Composites Part B: Engineering, v. 58, p. 371-377, 2014.

HAGARE, H. D. ; A. H. ; P. Water treatment plant residuals management. Water Sci Technol, v. 35, n. 8, p. 45-46, 1997.

ISMAIL, I. et al. Influence of fly ash on the water and chloride permeability of alkali-activated slag mortars and concretes. Construction and Building Materials, v. 48, p. 1187-1201, 2013. Disponível em: <http://dx.doi.org/10.1016/j.conbuildmat.2013.07.106>.

J. L. PROVIS, J. S. J. van D. Geopolymers Structures, Processing, Properties and Industrial Applications. v. 82, 2009.

KARIM, M. R. et al. Fabrication of a non-cement binder using slag, palm oil fuel ash and rice husk ash with sodium hydroxide. Construction and Building Materials, v. 49, p. 894-902, 2013. Disponível em: <http://dx.doi.org/10.1016/j.conbuildmat.2013.08.077>.

KENNE DIFFO, B. B. et al. Effect of the rate of calcination of kaolin on the properties of metakaolin-based geopolymers. Journal of Asian Ceramic Societies, v. 3, n. 1, p. 130-138, 2015.

LAHOTI, M. et al. Effects of Si/Al molar ratio on strength endurance and volume stability of metakaolin geopolymers subject to elevated temperature. Ceramics International, v. 44, n. 5, p. 5726-5734, 2018.

LEE, N. K.; JANG, J. G.; LEE, H. K. Shrinkage characteristics of alkali-activated fly ash/slag paste and mortar at early ages. Cement and Concrete Composites, v. 53, p. 239-248, 2014. Disponível em: <http://dx.doi.org/10.1016/j.cemconcomp.2014.07.007>.

MASTALI, M. et al. Drying shrinkage in alkali-activated binders - A critical review. Construction and Building Materials, v. 190, p. 533-550, 2018. Disponível em: 〈https://doi.org/10.1016/j.conbuildmat.2018.09.125>. 
NIMWINYA, E. et al. A sustainable calcined water treatment sludge and rice husk ash geopolymer. Journal of Cleaner Production, v. 119, p. 128-134, 2016. Disponível em: <http://dx.doi.org/10.1016/j.jclepro.2016.01.060>.

PACHECO-TORGAL, F. et al. An overview on the potential of geopolymers for concrete infrastructure rehabilitation. Construction and Building Materials, v. 36, p. 1053-1058, 2012. Disponível em: <http://dx.doi.org/10.1016/j.conbuildmat.2012.07.003>.

POUEY, M. T. F. Beneficiamentos da cinza de casca de arroz residual com vistas à produção de cimento composto e/ou pozolânico. p. 320, 2006. Disponível em: 〈http://hdl.handle.net/10183/7733〉.

PROVIS, J. L.; VAN DEVENTER, J. S. J. Geopolymers and Other Alkali-Activated Materials. 5. ed. [s.1.] Elsevier Ltd., 2019.

SANTOS, C. P. et al. Caracterização de argilas calcárias utilizadas na produção de revestimentos cerâmicos no Estado de Sergipe-Brasil. Ceramica, v. 62, n. 362, p. 147-156, 2016.

SANTOS, G. Z. B. et al. Synthesis of water treatment sludge ash-based geopolymers in an Amazonian context. Journal of Environmental Management, v. 249, n. December 2018, p. 109328, 2019. Disponível em: <https://doi.org/10.1016/j.jenvman.2019.109328>.

SANTOS, G. Z. B.; MELO FILHO, J. A.; MANZATO, L. Proposta de uma cerâmica obtida por meio de geopolimerização de lodo de ETA calcinado. Cerâmica, v. 64, n. 370, p. 276-283, 2018.

SUKSIRIPATTANAPONG, C. et al. Unit weight, strength and microstructure of a water treatment sludge-fly ash lightweight cellular geopolymer. Construction and Building Materials, v. 94, p. 807-816, 2015. Disponível em: <http://dx.doi.org/10.1016/j.conbuildmat.2015.07.091>.

TARTARI, R. et al. Nivaldo 57. v. 57, p. 288-293, 2011.

TEIXEIRA, S. R. et al. The effect of incorporation of a Brazilian water treatment plant sludge on the properties of ceramic materials. Applied Clay Science, v. 53, n. 4, p. 561-565, 2011. Disponível em: <http://dx.doi.org/10.1016/j.clay.2011.05.004>.

\section{UNITED NATIONS. World Population Prospects 2019. [s.l: s.n.]}

WAIJAREAN, N.; ASAVAPISIT, S.; SOMBATSOMPOP, K. Strength and microstructure of water treatment residuebased geopolymers containing heavy metals. Construction and Building Materials, v. 50, p. 486-491, 2014. Disponível em: <http://dx.doi.org/10.1016/j.conbuildmat.2013.08.047>.

WANG, H.; LI, H.; YAN, F. Synthesis and mechanical properties of metakaolinite-based geopolymer. Colloids and Surfaces A: Physicochemical and Engineering Aspects, v. 268, n. 1-3, p. 1-6, 2005.

YANG, T.; ZHU, H.; ZHANG, Z. Influence of fly ash on the pore structure and shrinkage characteristics of metakaolinbased geopolymer pastes and mortars. Construction and Building Materials, v. 153, p. 284-293, 2017. Disponível em: <http://dx.doi.org/10.1016/j.conbuildmat.2017.05.067>.

ZHANG, B.; MACKENZIE, K. J. D.; BROWN, I. W. M. Crystalline phase formation in metakaolinite geopolymers activated with $\mathrm{NaOH}$ and sodium silicate. Journal of Materials Science, v. 44, n. 17, p. 4668-4676, 2009.

ZHANG, J. et al. Properties of fresh and hardened geopolymer-based grouts. Ceramics - Silikaty, v. 63, n. 2, p. 164$173,2019$.

ZHANG, P. et al. A review on properties of fresh and hardened geopolymer mortar. Composites Part B: Engineering, v. 152, n. April, p. 79-95, 2018. Disponível em: 〈https://doi.org/10.1016/j.compositesb.2018.06.031〉.

ZHU, H. et al. Durability of alkali-activated fly ash concrete: Chloride penetration in pastes and mortars. Construction and Building Materials, v. 65, p. 51-59, 2014. Disponível em: <http://dx.doi.org/10.1016/j.conbuildmat.2014.04.110>. 